\title{
A new selective medium for Streptococcus pneumoniae
}

\author{
T NICHOLS AND R FREEMAN
}

From the Department of Microbiology, Freeman Hospital, Newcastle upon Tyne, UK

SUMmARY The development and evaluation of a new selective medium for Streptococcus pneumoniae is described. It is shown that the new medium (crystal violet-nalidixic acid-gentamicin agar:CVNG) is highly selective for Strep. pneumoniae in sputum specimens containing other organisms and is also sensitive, being only marginally inhibitory when compared to Columbia blood agar. The advantages of the medium in routine use are presented, based on 206 consecutive sputum specimens. It is concluded that CVNG medium is a useful adjunct to sputum bacteriology, especially in combination with digestion of the sputum samples by Cleland's reagent.

\section{Material and methods}

DEVELOPMENT OF THE MEDIUM

The medium devised by Masters et al. ${ }^{1}$ was taken as the starting point. This medium contains streptomycin $(2 \mu \mathrm{g} / \mathrm{ml})$ and crystal violet $(1$ in 500000$)$ in a blood agar base. It was found to be non-inhibitory to pneumococci and certain other streptococci, while preventing the growth of most aerobic Gramnegative bacilli, including Proteus species.

In view of the emergence of multiply resistant Gram-negative aerobic bacilli in recent years, it was decided to substitute gentamicin for the streptomycin. It was found that the minimum inhibitory concentration (MIC) for gentamicin of several recent clinical isolates of Streptococcus pneumoniae was around $16 \mu \mathrm{g} / \mathrm{ml}$. Gentamicin was used in the new medium at concentrations of 8 and $2 \mu \mathrm{g} / \mathrm{ml}$, and the testing leading to the adoption of $2 \mu \mathrm{g} / \mathrm{ml}$ as the final concentration is described below.

The crystal violet component of the original medium was retained, it being widely accepted that at the concentration used (1 in 500000$)$ it is selective for streptococci, including Strep. pneumoniae, while inhibiting staphylococci and other Gram-positive organisms. Because of the necessary reduction in the gentamicin concentration it was decided to add nalidixic acid to the medium at a concentration of $50 \mu \mathrm{g} / \mathrm{ml}$, this level having been used in other selective media recently described ${ }^{2}$ in order to prevent possible growth of some species, particularly the commensal neisseria. The medium was enriched by the addition

Received for publication 24 January 1980 of $10 \%$ horse blood, and the base medium selected was Columbia agar. The medium was designated crystal violet-nalidixic acid-gentamicin medium (CVNG). Antibiotics were added as sterile solutions after autoclaving.

EVALUATION OF THE MEDIUM

\section{Ability of medium to suppress contaminating organisms}

Recent clinical isolates of the following bacteria were plated on to the medium, which was then incubated overnight at $37^{\circ} \mathrm{C}$ and inspected for growth:

Staphylococcus aureus Proteus mirabilis

Corynebacterium species Klebsiella aerogenes

('diphtheroids') Klebsiella oxytoca

Streptococcus pyogenes Klebsiella atlanta

Streptococcus faecalis Escherichia coli

Streptococcus viridans Pseudomonas aeruginosa

Streptococcus pneu-

moniae

Haemophilus influenzae (the strain used was sensitive to gentamicin by disc diffusion testing).

All the above organisms were also plated on to Columbia blood agar and incubated under identical conditions. The results are seen in Table 1.

Sensitivity of medium to growth of Strep. pneumoniae Six clinical isolates of Strep. pneumoniae, all from blood cultures, were inoculated into tubes of Todd-Hewitt broth and incubated overnight. Serial dilutions of each broth were then made, in broth, ranging from 1 in 2 to 1 in 128. Using a Miles and Misra technique, aliquots of each dilution of each 
Table 1 Ability of various test organisms to grow on CVNG medium

\begin{tabular}{llll}
\hline Organism & Growth & Organism & Growth \\
\hline Staph. aureus & - & P. mirabilia & - \\
Diphtheroids & - & Kl. aerogenes & - \\
Strep. pyogenes & - & Kl. oxytoca & - \\
Strep. faecalis & + & Kl. atlanta & - \\
Strep. viridans & + & E. coli & - \\
Neisseria catarrhalis & - & Ps. aeruginosa & \pm \\
H. influenzae & - & Strep. pneumoniae & + \\
\hline
\end{tabular}

All organisms grew well on the control medium (Columbia blood agar).

*Although growth of Ps. aeruginosa occurred, the growth was scanty and much reduced when compared to the control medium.

broth were inoculated on to the surface of plates of the CVNG medium and on to plates of Columbia blood agar in parallel. Plates were incubated overnight, and comparisons were made of the number of colonies on the two media in each instance. This test was carried out in parallel on two batches of CVNG medium, one containing gentamicin at $8 \mu \mathrm{g} / \mathrm{ml}$ and the other at $2 \mu \mathrm{g} / \mathrm{ml}$. The results are seen in Table 2 .

\section{USE OF MEDIUM UNDER ROUTINE CONDITIONS}

Pilot study to assess advantages of anaerobiosis Thirty-four consecutive sputum specimens were taken from the routine laboratory and inoculated on to plates consisting of half CVNG and half Columbia blood agar in duplicate. One set of plates was then incubated in $10 \% \mathrm{CO}_{2}$ and the other parallel set of plates under anaerobic conditions (hydrogen $+10 \% \mathrm{CO}_{2}$ ), both at $37^{\circ} \mathrm{C}$, overnight. The isolation rate of Strep. pneumoniae and other organisms was contrasted and compared on both the CVNG and Columbia blood agar in both atmospheres. Sputum specimens were not digested in any way. The results are seen in Table 3.

\section{Use of medium in conjunction with digestion of sputum samples}

Two hundred and six consecutive sputum samples

Table 2 Comparative viable counts of Strep. pneumoniae on CVNG medium (at two formulations) and Columbia blood agar

\begin{tabular}{|c|c|c|c|}
\hline \multirow[t]{2}{*}{ Dilution of broth culture } & \multicolumn{3}{|c|}{ Viable counts of Strep. pneumoniae (actual number $\times$ dilution) } \\
\hline & Columbia blood agar & CVNG medium 1 & CVNG medium 2 \\
\hline $\begin{array}{l}\text { Neat } \\
1 \text { in } 2 \\
1 \text { in } 4 \\
1 \text { in } 8 \\
1 \text { in } 16 \\
1 \text { in } 32 \\
1 \text { in } 64 \\
1 \text { in } 128\end{array}$ & $\begin{array}{r}>100000 \\
>100000 \\
>100000 \\
>100000 \\
92000 \\
49000 \\
21000 \\
18000\end{array}$ & $\begin{array}{r}>100000 \\
>100000 \\
>100000 \\
71000 \\
67000 \\
37000 \\
16000 \\
11000\end{array}$ & $\begin{array}{r}>100000 \\
>100000 \\
48000 \\
32000 \\
18000 \\
10000 \\
4000 \\
2000\end{array}$ \\
\hline
\end{tabular}

CVNG medium 1 contained gentamicin at a concentration of $2 \mu \mathrm{g} / \mathrm{ml}$. CVNG medium 2 contained gentamicin at a concentration of $8 \mu \mathrm{g} / \mathrm{ml}$.

The counts detailed above are the mean of six experiments with six different clinical strains of Strep. pneumoniae.

Table 3 Comparison of isolation rates* of various organisms from 34 consecutive sputum samples using $C V N G$ medium and Columbia blood agar in atmospheres of $\mathrm{CO}_{2}$ and hydrogen $+10 \% \mathrm{CO}_{2}$ (anaerobiosis)

\begin{tabular}{|c|c|c|c|c|}
\hline \multirow[t]{3}{*}{ Organism } & \multicolumn{4}{|c|}{ Atmosphere } \\
\hline & \multicolumn{2}{|c|}{ Carbon dioxide } & \multicolumn{2}{|c|}{ Anaerobiosis } \\
\hline & $C V N G$ & Columbia & $C V N G$ & Columbia \\
\hline $\begin{array}{l}\text { Strep. pneumoniae } \\
\text { Strep. viridans } \\
\text { Strep. faecalis } \\
\text { Coagulase-negative staphylococci } \\
\text { Staph. aureus } \\
\text { H. infuenzae } \\
\text { Klebsiellae } \\
\text { E. coli } \\
\text { Proteus species } \\
\text { Miscellaneous } \dagger\end{array}$ & $\begin{array}{r}5 \\
14 \\
3 \\
0 \\
0 \\
0 \\
0 \\
0 \\
0 \\
0\end{array}$ & $\begin{array}{r}5 \\
13 \\
3 \\
10 \\
5 \\
2 \\
5 \\
7 \\
2 \\
6\end{array}$ & $\begin{array}{r}5 \\
13 \\
6 \\
0 \\
0 \\
0 \\
0 \\
0 \\
0 \\
0\end{array}$ & $\begin{array}{r}5 \\
13 \\
5 \\
10 \\
5 \\
2 \\
2 \\
8 \\
2 \\
8\end{array}$ \\
\hline
\end{tabular}

*The number of isolates exceeds the number of specimens when totalled since some specimens yielded more than one variety of organism. †This category includes 'diphtheroids' and some Bacillus species. 
from the routine laboratory were obtained, and their macroscopic appearance was noted. Appearance was recorded as: purulent, mucopurulent $(+)$, mucopurulent $( \pm)$, and mucoid. Each specimen was then inoculated on to a plate of half CVNG medium and half Columbia blood agar. The residue of the sputum sample was digested with Cleland's reagent (Sputolysin) by adding an equal volume of the lytic reagent to the sputum, agitating the mixture for 5 minutes, and then allowing the mixture to stand for 5 minutes, this cycle being repeated to a total time of 20 minutes, all at ambient temperature. The resultant fiuid was inoculated on to plates of half CVNG medium and half Columbia blood agar as before. All plates were incubated overnight at $37^{\circ} \mathrm{C}$. in an atmosphere of $10 \% \mathrm{CO}_{2}$ and inspected for the growth of pneumococci and other organisms. The results are presented in Table 4.

All organisms isolated in this study were identified by standard methods, sensitivity to optochin being taken as the definitive test for pneumococci.

Finally, the Figure illustrates the appearances seen on a plate consisting of half CVNG and half Columbia blood agar of a sputum specimen containing Strep. pneumoniae contaminated with $\mathrm{Kl}$. aerogenes.

\section{Results}

Table 1 shows that, of the organisms inoculated on to

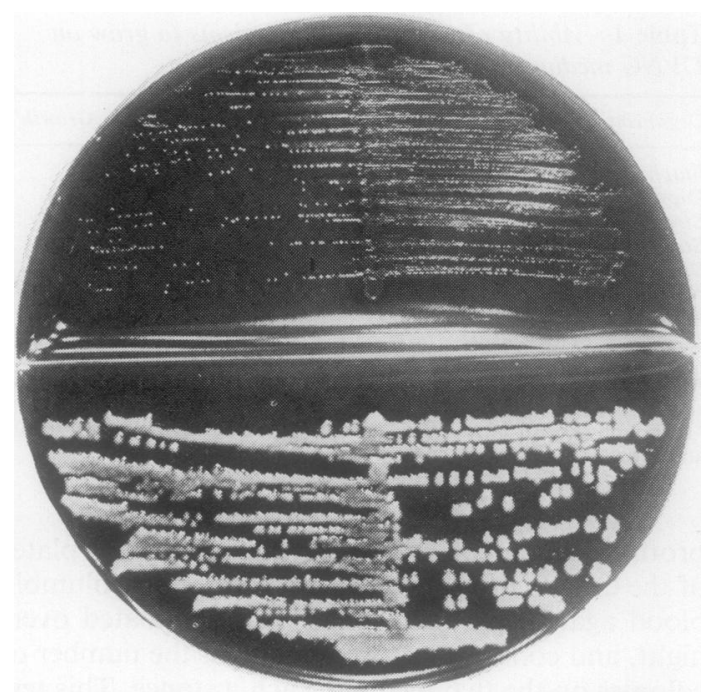

The lower half of the plate consists of Columbia blood agar, and the profuse growth of $\mathrm{Kl}$. aerogenes is seen. Strep. pneumoniae is not seen. The upper half of the plate consists of CVNG medium and Strep. pneumoniae is seen in pure culture.

the CVNG medium, only the alpha-haemolytic streptococci ('Strep. viridans' and Strep. pneumoniae) and the faecal streptococci were capable of growth.

Table 4 Number of isolations of various organisms and organism-groups from 206 consecutive sputum samples, grouped according to macroscopic appearance regarding purulence (see text)

\begin{tabular}{|c|c|c|c|c|c|c|c|c|}
\hline \multirow[t]{3}{*}{ Organism } & \multicolumn{4}{|c|}{ Purulent sputum (48 specimens) } & \multicolumn{4}{|c|}{ Mucopurulent sputum $(+)(53$ specimens $)$} \\
\hline & \multicolumn{2}{|l|}{ Digested } & \multicolumn{2}{|c|}{ Undigested } & \multicolumn{2}{|l|}{ Digested } & \multicolumn{2}{|c|}{ Undigested } \\
\hline & $C V N G$ & $C B A$ & $C V N G$ & $C B A$ & $C V N G$ & $C B A$ & $C V N G$ & $C B A$ \\
\hline $\begin{array}{l}\text { Strep. pneumoniae } \\
\text { Other streptococci } \\
\text { Staphylococci } \\
\text { H. influenzae } \\
\text { Other organisms* } \\
\text { No growth }\end{array}$ & $\begin{array}{l}11(23) \\
37(77) \\
0 \\
0 \\
2(4) \\
8(17)\end{array}$ & $\begin{array}{r}9(19) \\
35(73) \\
9(19) \\
11(23) \\
18(37) \\
3(6)\end{array}$ & $\begin{array}{l}11(23) \\
42(87) \\
0 \\
0 \\
2(4) \\
7(14)\end{array}$ & $\begin{array}{c}8(17) \\
39(81) \\
10(21) \\
10(20) \\
17(35) \\
3(6)\end{array}$ & $\begin{array}{l}7(13) \\
59(111) \\
0 \\
0 \\
0 \\
7(13)\end{array}$ & $\begin{array}{c}4(7) \\
59(111) \\
13(24) \\
17(32) \\
14(26) \\
2(4)\end{array}$ & $\begin{array}{l}5(9) \\
57(107) \\
0 \\
0 \\
0 \\
7(13)\end{array}$ & $\begin{array}{c}4(7) \\
55(103) \\
14(26) \\
19(35) \\
18(34) \\
2(4)\end{array}$ \\
\hline \multirow[t]{3}{*}{ Organism } & \multicolumn{4}{|c|}{ Mucopurulent sputum $( \pm)$ (52 specimens) } & \multicolumn{4}{|c|}{ Mucoid sputum (53 specimens) } \\
\hline & \multicolumn{2}{|l|}{ Digested } & \multicolumn{2}{|c|}{ Undigested } & \multicolumn{2}{|l|}{ Digested } & \multicolumn{2}{|c|}{ Undigested } \\
\hline & $C V N G$ & $C B A$ & $C V N G$ & $C B A$ & $C V N G$ & $C B A$ & CVNG & $C B A$ \\
\hline $\begin{array}{l}\text { Strep. pneumoniae } \\
\text { Other streptococci } \\
\text { Staphylococci } \\
\text { H. influenzae } \\
\text { Other organisms* } \\
\text { No growth }\end{array}$ & $\begin{array}{l}5(10) \\
60(115) \\
0 \\
0 \\
1(2) \\
3(6)\end{array}$ & $\begin{array}{l}5(10) \\
50(96) \\
13(25) \\
14(27) \\
15(29) \\
0\end{array}$ & $\begin{array}{l}5(10) \\
65(125) \\
0 \\
0 \\
0 \\
4(7)\end{array}$ & $\begin{array}{l}3(6) \\
55(105) \\
17(33) \\
15(29) \\
16(29) \\
0\end{array}$ & $\begin{array}{l}1(2) \\
63(123) \\
0 \\
0 \\
0 \\
3(6)\end{array}$ & $\begin{array}{l}0 \\
56(109) \\
15(29) \\
11(21) \\
17(33) \\
0\end{array}$ & $\begin{array}{l}0 \\
62(116) \\
0 \\
0 \\
0 \\
4(8)\end{array}$ & $\begin{array}{l}0 \\
56(105) \\
17(33) \\
10(20) \\
16(31) \\
0\end{array}$ \\
\hline
\end{tabular}

The number and percentage isolations exceeds the number of specimens where more than one member of an organism-group was recovered from the same specimen.

Percentages in parentheses.

*The three organisms in this group that grew on CVNG were all pseudomonas. 
Ps. aeruginosa showed slight growth, but all other organisms were suppressed, although all grew on the control medium.

Table 2 shows that Strep. pneumoniae grows well on CVNG medium, but also that the concentration of gentamicin is critical. Thus, the medium is markedly inhibitory compared to Columbia blood agar when gentamicin is present at $8 \mu \mathrm{g} / \mathrm{ml}$, but this effect is much reduced at $2 \mu \mathrm{g} / \mathrm{ml}$.

From Table 3 it can be seen that no obvious advantage is obtained by the use of anaerobiosis, and it was thus decided that the more laborious technique of anaerobic culture was unnecessary, $10 \%$ $\mathrm{CO}_{2}$ being preferred for future experiments. However, Strep. pneumoniae was recovered well from the medium under anaerobic conditions, and the possibility of using this on the rare occasion when significant contamination with Ps. aeruginosa was present should not be discounted.

Table 4 reveals the effects of sputum digestion, CVNG medium, and the combination. It is seen that the use of sputum digestion increases the yield of Strep. pneumoniae, as does the use of CVNG medium alone, but that the highest yield occurs when the two methods are combined.

The Figure illustrates the dramatic effect of CVNG medium in recovering Strep. pneumoniae from sputum samples in which a luxuriant growth of contaminants would be the only result of culture on conventional media.

\section{Discussion}

The results show that CVNG medium is selective for streptococci of alpha-haemolytic and faecal type, including Strep. pneumoniae. Although growth on the medium is insufficient of itself to identify Strep. pneumoniae it has been found that most workers rapidly acquire the ability to distinguish the organism from other streptococci. The medium, while selective, appears to be non-inhibitory to Strep. pneumoniae, and resort to anaerobiosis is unnecessary, although use of anaerobic conditions might be useful in rare instances in which Ps. aeruginosa is also present.

The critical nature of the gentamicin concentration demonstrated here serves to explain the unfavourable report of a previous study using this antibiotic in a selective medium for Strep. pneumoniae. ${ }^{3}$

Under routine conditions the medium performs well, increasing the yield of Strep. pneumoniae from clinical specimens, especially when used together with digestion techniques. The limitations of the medium are obvious. It cannot be used as the sole medium for sputum bacteriology since other sputum pathogens will not be isolated, and it will not contribute to the problem posed by patients in whom pre-existing antibiotic therapy has occurred other than by suppressing overgrowth due to contaminants.

This work is to be submitted by Trevor Nichols as a project report for the Special Examination in Microbiology.

\section{References}

1 Masters PL, Brumfitt W, Mendez RL, Likar M. Bacterial flora of the upper respiratory tract in Paddington families, 1952-54. Br Med J 1958;1:1200-5.

2 Ingham HR, Dutton J, Sisson PR, Sprott MS, Selkon JB. An aid to the preliminary identification of non-sporing anaerobes. J Clin Pathol 1978;31:806-7.

${ }^{3}$ Schmidt RE, Washington JA, Anhalt JP. Gentamicinblood agar for isolation of Streptococcus pneumoniae from respiratory secretions. J Clin Microbiol 1978;7:426-7.

Requests for reprints to: Dr R Freeman, Freeman Hospital, Freeman Road, High Heaton, Newcastle upon Tyne NE7 7DN, UK. 